\title{
Goldchipelektroden zur elektrochemischen DNA-Detektion
}

\author{
Sandra M. Bütow, Oliver Pänke, Jan Kafka, Fred Lisdat
}

\section{Zusammenfassung}

Im folgenden Artikel werden einfache DNA-Sensoren vorgestellt, mit deren Hilfe es durch voltammetrische und impedimetrische Messmethoden möglich ist, schnell, sensitiv und kostengünstig Einzelstrang-DNA (ssDNA) nachzuweisen. Beide Messprinzipien lassen neben der spezifischen Detektion auch die Quantifizierung von DNA-Sequenzen sowie den Nachweis von einzelnen Basenfehlpaarungen innerhalb dieser Sequenzen zu. Fänger-DNA wurde zu diesem Zweck mit dem 5'-Ende auf einer Goldoberfläche immobilisiert. Die Hybridisierung mit einem Methylenblau (MB) markierten oder unmarkierten Probenstrang konnte dann mit Hilfe der Differenzpulsvoltammetrie DPV oder der elektrochemischen Impedanzspektroskopie nachgewiesen werden. Die voltammetrische Quantifizierung erfolgte in einem direkten und kompetitiven Ansatz, mit einem Detektionslimit von $30 \mathrm{nM}$ bzw. $3 \mathrm{nM}$ (bei Einsatz von 0,1 $\mu \mathrm{M}$ Kompetitor-DNA). Das Detektionslimit beim impedimetrischen Nachweis lag bei 100 nM DNA. Die hier vorgestellten Sensoren sind zum einen regenerierbar und können zum anderen über einen Zeitraum von zwei Monaten gelagert werden.

\section{Abstract}

This paper describes simplistic electrochemical DNA sensors for the sensitive, more rapid and cost effective detection of single-stranded DNA (ssDNA). The used methodes are the voltammetric detection and the detection by impedance spectroscopy. Beside the specific detection of ssDNA both techniques allow quantification of DNA and verification of single base pair mismatches within the sequences. Therefore a single-stranded 18mer oligonucleotide (DNA) was immobilised via a thiol-linker on gold film electrodes and served as probe DNA. Hybridisation was detected by means of the electroactive redox-marker methylene blue (MB), which was covalently bound to the 5 '-end of the target DNA, by differential pulse voltammetry (DPV) or by measuring the differences in the charge transfer resistance $\left(\mathrm{R}_{\mathrm{CT}}\right)$ by electrochemical impedance spectroscopy (EIS) using non-labelled ssDNA targets. MB-labelled target DNA was verified down to $30 \mathrm{nM}$ DNA. By application of a competitive binding assay non-labelled DNA was detected down to 3 nM DNA. The detection limit for impedimetric DNA sensors was $100 \mathrm{nM}$ ssDNA. The sensors were found to be reusable and could be stored for more than two month at $4{ }^{\circ} \mathrm{C}$ without significant loss in their activity.

\section{Einleitung}

Die schnelle Detektion und Quantifizierung von Nukleinsäuren bzw. die Sequenzierung von Nukleotidabfolgen sind auf Grund der schnell voranschreitenden Genomforschung in vielen Anwendungsbereichen und analytischen Laboratorien von besonderem Interesse. Nicht nur die medizinische Diagnostik, deren Aufgabe unter anderem die Detektion von genetisch bedingten Krankheiten ist oder die Forensik, für die der Nachweis von Verwandschaftsverhältnissen ein zentrales Thema darstellt, sind auf schnelle, einfache und sensitive Nachweismethoden für DNA-Sequenzen angewiesen.
Immer deutlicher tritt zudem hervor, dass es von entscheidender Bedeutung ist, Viren, Bakterien oder mikrobielle Kontaminationen in Lebensmitteln einfach und schnell nachweisen zu können [1, 2]. Dabei spielt der Nachweis von Hybridisierungsvorgängen zwischen DNA-Einzelsträngen eine große Rolle. Im letzten Jahrzehnt fokussierten viele Arbeitsgruppen ihre Arbeiten auf den Nachweis der Hybridisierung mit Hilfe von Fluoreszenzmarkern [z. B. 3]. Daneben wurden auch Untersuchungen mit Hilfe der Massenspektrometrie [4], Quarz-Mikrowaage [5], der Oberflächenplasmonresonanz-Spektroskopie [6] und elektrochemischen Methoden durchgeführt [7-12]. 
Die Nachfrage nach kleinen, einfachen, kostengünstigen und unter Umständen auch transportablen Nachweissystemen führte zur Entwicklung von zahlreichen elektrochemischen Biosensoren und DNA-Chips. Diesen Biosensoren ist ein Aufbauprinzip gemein: Ein DNA-Fängerstrang (Probe) wird auf der Sensoroberfläche immobilisiert. Der Kontakt mit komplementärer Ziel-DNA (Target) führt zu einer Hybridisierungsreaktion. Der Einbau eines Redoxmarkers in die Targetsequenz oder in die dsDNA (Interkalation) ermöglicht im Anschluss eine Auslese des Sensors. Die einzelnen DNA-Sensoren unterscheiden sich dabei hauptsächlich in der Wahl der verwendeten Redoxspezies. Bei der voltammetrischen Detektion werden z. B. Metallkomplexe auf der Basis von Kobalt, Osmium oder Ruthenium [13-15] oder auch organische Verbindungen wie Methylenblau (MB), Daunomycin, Hoechst 33258 oder Anthrachionderivate [16-18] verwendet. Die Verwendung von redoxaktiven Stoffen bringt jedoch immer einen zusätzlichen Arbeitsschritt und Kosten mit sich. Aus diesem Grunde gibt es Bestrebungen, markierungsfreie Detektionsmöglichkeiten zu entwickeln. So wurde in verschiedenen Arbeiten z. B. die katalytische Oxidation von Guanidin zur Detektion der Hybridisierung verwendet [z. B. 19]. Aber auch der elektrische Widerstand [20] oder die Kapazität [21] einer Oberfläche zeigen Änderungen in der Oberflächenbeschaffenheit sehr sensitiv an und bieten somit eine weitere Möglichkeit zur Detektion von Hybridisierungsereignissen. Bei der elektrochemischen Impedanzspektroskopie ist die Messung beider Parameter möglich. Heutige Geräte bieten dabei die Möglichkeit Impedanzspektren über einen breiten Frequenzbereich aufzuzeichnen, was dann eine umfassende Charakterisierung der Oberfläche innerhalb einer Messung zulässt.

In diesem Artikel zeigen wir einfach aufgebaute DNASensoren, die mit verschiedenen elektrochemischen Messmethoden, wie der voltammetrischen Detektion (CV, DPV) oder der Impedanzspektroskopie (EIS), in der Lage sind, sowohl unbekannte Mengen an Einzelstrang DNA zu quantifizieren, als auch einzelne Basenfehlpaarungen zuverlässig zu detektieren. Die Detektion kann dabei sowohl mit unmarkierten, als auch mit dem redoxaktiven Methylenblau (MB) markierten ssDNA-Strängen durchgeführt werden.

\section{Material und Methoden}

Thiol-modifizierte Einzelstrang-DNA (ss-DNA) wurde über die Firma Thermo-Electron (Ulm, Germany) bezogen. Die Thiolgruppe war über einen C6-Linker am 5'-Ende mit der Sequenz verbunden: $\mathrm{HS}_{-} \mathrm{C}_{6}$-CCT CGT AGG CAA TCG TTC-3'. Die DNA-Konzentration wurde photometrisch bei $260 \mathrm{~nm}$ bestimmt und der Gehalt an freien Thiolgruppen wurde mit Hilfe des Ellmanns Reagenz [22] überprüft. Alle ssDNA-Targets wurden von BioTez (Berlin-Buch, Deutschland) geliefert. Die Modifikation dieser DNA mit dem redoxaktiven Marker Methylenblau (MB) erfolgte am 5'-Ende der Sequenz über einen Aminlinker durch die Firma emp Biotech (Berlin-Buch, Deutschland). Die verwendeten Sequenzen dieser Studie sind in Tabelle 1 dargestellt. Die DNA-Stränge bestanden aus 18 Basen (18mer) und waren zusätzlich mit HPLC aufgereinigt. Alle anderen verwendeten Chemikalien wurden über Sigma-Aldrich (Taufkirchen, Deutschland) oder Merck (Darmstadt, Deutschland) bezogen und ohne weitere Aufreinigung verwendet. Zum Ansetzen der Lösungen wurde deionisiertes Wasser aus einem Millipore MilliQ-System verwendet.

\begin{tabular}{|l|l|}
\hline Name & Sequence $\left(5^{\prime} \rightarrow 3^{\prime}\right)$ \\
\hline komplementäre ssDNA $(\mathbf{c})$ & GAA CGA TTG CCT ACG AGG \\
\hline ssDNA (GA14) & GAA CGA TTG CCT AAG AGG \\
\hline ssDNA (GG14) & GAA CGA TTG CCT AGG AGG \\
\hline ssDNA (GT14) & GAA CGA TTG CCT ATG AGG \\
\hline ssDNA (AC08) & GAA CGA TCG CCT ACG AGG \\
\hline ssDNA (TT03) & GAT CGA TTG CCT ACG AGG \\
\hline nicht-kompl. ssDNA $(\mathbf{n})$ & CCT CGT AGG CAA TCG GCG \\
\hline
\end{tabular}

Tabelle 1: Verwendete DNA-Sequenzen

\section{Reinigung der Goldchipelektroden}

Die verwendeten Goldelektroden bestanden aus einer 200 nm dicken Goldschicht, aufgetragen auf einen Siliziumwafer und wurden vom Forschungszentrum Jülich (Prof. Schöning, Deutschland) bezogen. Die Elektrodenoberfläche hatte eine Fläche von $0,2 \mathrm{~cm}^{2}$. Zur Reinigung der Oberfläche vor der Beschichtung erfolgten zwei Inkubationen von jeweils 15 min in Aceton gefolgt von Isopropanol im Ultraschallbad bei $50{ }^{\circ} \mathrm{C}$. Daran anschließend wurden die Elektroden für $1 \mathrm{~h}$ in frisch bereiteter „hot Piranha-Lösung“ (67\%, v/v, konzentrierte $(98 \%)$ Schwefelsäure und $33 \%$ Wasserstoffperoxid (33\%)) gereinigt. Hier ist besondere Vorsicht geboten, da »Piranha-Lösung « bei der Herstellung extrem heiß 
wird. Nach jedem Schritt wurden die Elektroden gründlich mit deionisiertem Wasser gespült.

\section{Immobilisierung der Fänger-DNA und Passivierung der Oberfläche}

Für die Immobilisierung der jeweiligen Fängersequenzen wurden die Elektroden im Anschluss an die Reinigung für $2 \mathrm{~h}$ in 0,1 M Natriumphosphatpuffer ( $\mathrm{pH} 7$ ), der $1 \mu \mathrm{M}$ thiolmodifizierten Fänger, $1 \mathrm{M}$ Kaliumchlorid und 2 mM Magnesiumchlorid enthielt inkubiert. Nach der Immobilisierung der ssDNA erfolgte ein Passivierungsschritt mit $1 \mathrm{mM}$ 4-Mercapto-1-butanol (MCB) im Immobilisierungspuffer über Nacht, um unspezifisch auf der Oberfläche angelagerte DNA-Stränge zu entfernen. Die Hybridisierung der Fänger mit ssDNATargets wurde in einem $50 \mathrm{nM}$ Tris-(hydroxymethylaminoethan-Puffer (TRIS/HCl, pH 7) mit $10 \mu \mathrm{M}$ ssDNA und $100 \mathrm{mM}$ Natriumchlorid durch 10 min Inkubation durchgeführt.

Alle voltammetrischen Untersuchungen wurden mit Hilfe eines $\mu$ Autolab Potentiostaten (Metrohm, Filderstadt, Germany) und einer $1 \mathrm{ml}$ Messzelle durchgeführt. Dabei bildete die modifizierte Goldchipelektrode die Arbeitselektrode, eine Ag | AgCl | 3M KCl Elektrode (Microelectrodes, Bedford, USA) die Referenzelektrode und ein Platindraht $(0,5 \mathrm{~mm}$, GoodFellow, Huntington, England) die Gegenelektrode der Drei-ElektrodenAnordnung. Die Messungen erfolgten in einem 0,1 M Natriumphosphatpuffer mit dem pH 7 (Messpuffer). Vor den Messungen wurde der Puffer mit Stickstoff gespült, um darin gelösten Sauerstoff zu entfernen. Bei der Messung wurde der Puffer nicht gerührt.

\section{Voltammetrische Messungen}

Die zyklovoltammetrischen Messungen zur Berechung der Oberflächenbelegung wurden mit einer Scanrate von $100 \mathrm{mVs}^{-1}$ im Bereich $0 \mathrm{~V}$ bis $-0,4 \mathrm{~V}$ in Messpuffer durchgeführt.

Bei der Differenzpulsvoltammetrie (DPV) wurde mit den folgenden Parametern gemessen: $25 \mathrm{mV}$ Pulsamplitude, $5 \mathrm{mV}$ Steppotential, $50 \mathrm{~ms}$ Pulsbreite und 0,5 s Pulsdauer. Die Messungen starteten bei OV und endeten bei $-400 \mathrm{mV}$. Vor der Messung wurde eine Spannung von $0 \mathrm{~V}$ über $60 \mathrm{~s}$ angelegt, um eine komplette Oxidation des $\mathrm{MB}$ sicherzustellen. Alle Experimente wurden bei Raumtemperatur $\left(22 \pm 2^{\circ} \mathrm{C}\right)$ durchgeführt. Die erhaltenen Messdaten wurden mir der GPES 4.7 Software der Firma EcoChemie/Metrohm (Filderstadt, Deutschland) ausgewertet.

\section{Impedimetrische Messungen}

Die impedimetrischen Messungen mit der Elektrochemischen Impedanzspektoskopie (EIS) erfolgten in derselben Messzelle wie zuvor die voltammetrischen Messungen. Es wurde ein Autolab PGSTAT 20 Gerät, ausgestattet mit einem FRA-Modul der Firma Metrohm (Filderstadt, Deutschland) verwendet. Die Impedanz wurde für das Hexacyanoferrat-System $\left(\left[\mathrm{Fe}(\mathrm{CN})_{6}\right]^{3-} /\right.$ $\left[\mathrm{Fe}(\mathrm{CN})_{6}\right]^{4-}$, je $\left.5 \mathrm{mM}\right)$ in $\mathrm{N}_{2}$-gespültem Messpuffer unter OCP-Bedingungen gemessen. Es wurden Frequenzen zwischen $10 \mathrm{kHz}$ und 0,3 Hz in logarithmischem Abstand bei $10 \mathrm{mV}$ Amplitude gewählt. Die Auswertung der gemessenen Impedanzspektren erfolgte über ein Ersatzschaltbild mit konstantem Phasenelement (CPE) und Lösungswiderstand, die in Reihe geschaltet die Versuchsanordnung zufriedenstellend wiedergeben. Der $\alpha$-Werte des CPEs lag zwischen 0,96 und 0,99.

Jede DNA-modifizierte Elektrode konnte üblicherweise für 12 Durchgänge (Hybridisierung/Denaturierung) verwendet werden. Die Denaturierung der Doppelstränge erfolgte mit $8 \mathrm{M}$ Harnstoff-Lösung für $30 \mathrm{~s}$. Vor jeder Messung (DPV oder EIS), d. h. nach jedem Hybridisierungs- bzw. Denaturierungsschritt wurde die Zelle mehrfach mit Messpuffer gespült.

Bei beiden Messmöglichkeiten ist eine leichte Abnahme des Peakstroms bzw. eine Zunahme des Durchtrittswiderstandes als Alterungserscheinung bei wiederholten Hybridisierungs-/Denaturierungszyklen zu verzeichnen. Aus diesem Grund wurden die Messwerte zur besseren Vergleichbarkeit unterschiedlicher Messungen normalisiert.

Dazu erfolgte jede zweite oder dritte Hybridisierung mit $10 \mu \mathrm{M}$ komplementärer ssDNA zur Generierung von Referenzwerten. Diese interpolierten Werte wurden im Anschluss als Referenzsignal für die unter anderen Bedingungen gemessenen Hybridisierungs-/Denaturierungszyklen verwendet.

\section{Ergebnisse und Diskussion}

\subsection{Voltammetrische DNA-Detektion}

Das Prinzip der voltammetrischen DNA-Detektion ist in Abbildung 1A dargestellt. Bei der DNA-Detektion mit Hilfe der Voltammetrie (Zyklische Voltammetrie CV oder Differenzpulsvoltammetrie DVP) erfolgt der Nachweis der Hybridisierung des Fängers mit einer komplementären DNA-Sequenz über die Redoxumwandlung eines gebundenen Markers. Dabei wurde Methylenblau 
A
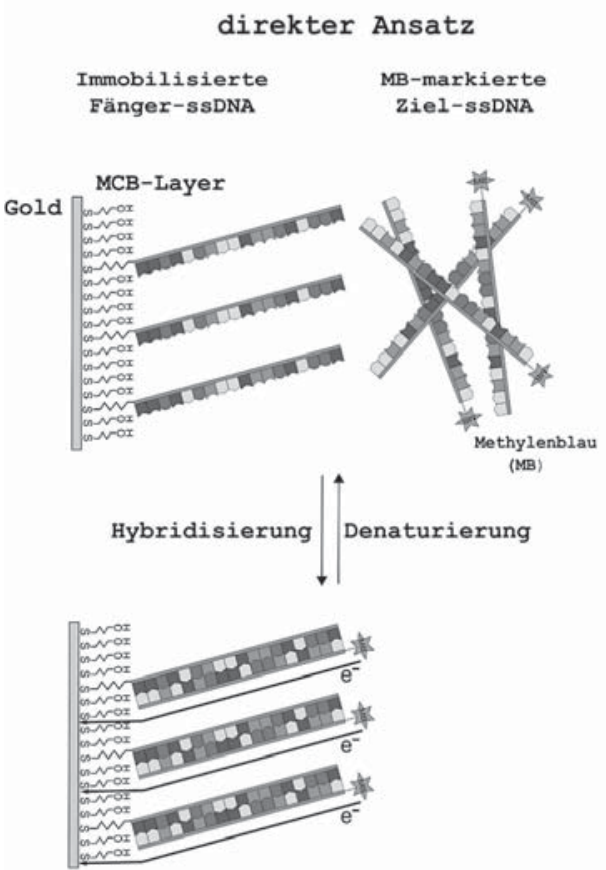

B

kompetitiver Ansatz

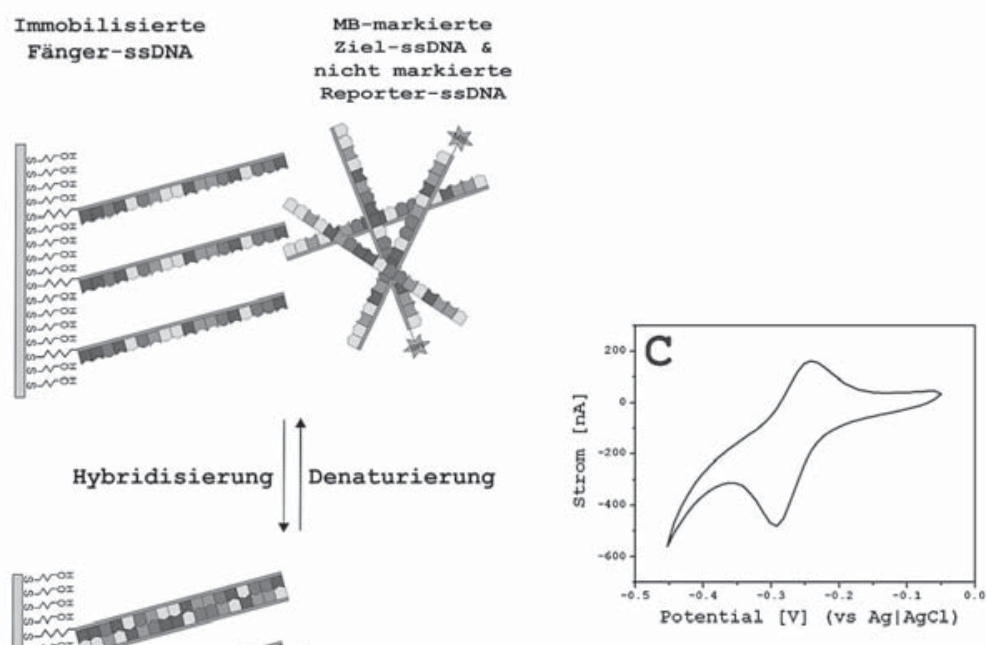

Abb. 1: Funktionsprinzip eines voltammetrisch auszuwertenden DNA-Sensors. A) Quantitativer Nachweis von MB-markierter DNA in einem direkten Ansatz und B) von nicht markierter DNA in einem kompetitiven Ansatz. C) Typisches Zyklovoltammogramm eines Sensors nach der Hybridisierung mit komplementärer MB-markierter Ziel-DNA.

(MB) über eine kovalente Bindung an die Target-DNA gebunden. Ist die markierte Zielsequenz komplementär und hat die Möglichkeit, mit der Fänger-DNA zu hybridisieren, entsteht ein Doppelstrang mit fest gebundenem Redoxmarker. Bei Aufprägung eines Potentials kann dann ein Austausch von Elektronen zwischen dem Redoxmarker Methylenblau und der Goldoberfläche erfolgen (s. Abb. 1A). Durch die Elektronenübertragung erfolgt ein Stromfluss, abhängig von der gewählten Methode sichtbar durch einen oder zwei charakteristische Peaks (s. Abb. 1C bzw. Abb. 2A).

Zur Charakterisierung der präparierten Elektroden, die sowohl für die voltammetrischen Messungen mit DPV als auch für die impedimetrischen Messungen mit EIS verwendet werden sollten, wurden vor jeder Versuchsreihe die Oberflächenbelegung und die Peaklage des Oxidations- bzw. Reduktionspeaks mit Hilfe der Zyklovoltammetrie (CV) bestimmt. Dazu erfolgte eine Hybridisierung mit $10 \mu \mathrm{M}$ komplementärer, MB-markierter ssDNA.

Die Auswertung von 20 Elektroden ergab ein formales Potential von -260 mV gegen Ag | AgCl. Dieses Ergebnis stimmt mit dem von Boon et al. 2003 bestimmten Wert von -265 mV für in DNA eingelagertes MB überein [23]. Die Oberflächenbelegung kann über eine Integ- ration der Peakflächen berechnet werden. Die Menge an immobilisierter DNA ist dabei proportional zu der Menge an hybridisierter ssDNA-MB und damit auch proportional zur Peakfläche. Die Oberflächenbelegung für dsDNA wurde mit 4-6 pmolcm ${ }^{-2}$ berechnet, was in derselben Größenordnung liegt, wie die in der Literatur beschriebenen Werte [13, 24, 25]. Eine hypothetische, maximale Oberflächenbelegung von 34 pmolcm $^{-2}$ kann über den Durchmesser der dsDNA-Helix (2,37 nm, Typ B-Struktur) und die Annahme einer dichtesten Packung berechnet werden. Auf Grundlage dessen haben die DNA-Sensoren eine Belegung ca. 12\%.

Die Denaturierung der Sensoren mit Harnstofflösung ermöglicht eine Verwendung der Elektroden für bis zu 12 Zyklen (Hybridisierung/Denaturierung). Die präparierten Elektroden konnten bei $4{ }^{\circ} \mathrm{C}$ über zwei Monate ohne signifikanten Signalverlust gelagert werden.

Nach der Charakterisierung der präparierten Elektroden erfolgten die Folgeexperimente mit der Differenzpulsvoltammetrie (DPV). Bei der DPV gibt der Stromverlauf bei einer gepulst angelegten Spannung Aufschluss über die Faradayschen Prozesse, die an der Oberfläche der Arbeitselektrode ablaufen. Die Spannungspulse in Kombination mit einer Strommessung zu definierten Zeitpunkten bieten dabei den Vorteil, dass der Faraday- 
sche Strom weitestgehend ohne den störenden kapazitiven Strom detektiert werden kann. Dieses macht diese Methodik im Gegensatz zur CV wesentlich sensitiver, auch geringe Faradaysche Ströme können somit noch zufriedenstellend detektiert werden.

\section{Spezifität des voltammetrischen DNA-Sensors}

Die Bindungsspezifität der DNA-modifizierten Elektroden wurde durch die Hybridisierung des Sensors mit komplementärer und nicht-komplementärer ZielDNA getestet. In Abbildung 2A und 2B sind die Ergebnisse von verschiedenen DPV-Messungen einer Elektrode und die dazugehörigen Peakströme gezeigt. Die Hybridisierung mit MB-markierter komplementärer Ziel-DNA zeigt einen starken Peak bei -250 mV. Die Messung des Sensors nach einer Denaturierung zeigte nur noch einen kleinen Peak, der unspezifisch gebundenen Ziel-DNA zuzuschreiben ist. Die Hybridisierung mit nicht komplementärer ssDNA, die ebenfalls MB markiert war, zeigte ebenfalls nur einen geringen Peak. Dieser ist vermutlich verursacht durch eine partielle Hybridisierung der nicht komplementären DNA mit dem Fänger. Bei einem Versatz der Zielsequenz um fünf Basen gegen die Fängersequenz können sieben Basenpaare hybridisieren, die eine schwache Bindung der Sequenzen verursachen könnten. Durch Hybridisierung mit einer vollständig nichtkomplementären Sequenz, bei der keine Teilpassfähigkeit vorhanden war, konnte dieser Peak nochmals verkleinert werden. Damit ist deutlich, dass es sich um einen hochspezifischen Sensor handelt.

Bei einer wiederholten Inkubation der Elektrode mit komplementärer ssDNA konnten $92 \%$ des zuerst gemessenen Signals erhalten werden. Die leichte Verringerung des Signals wird durch die Denaturierungsprozedur verursacht und wurde für Folgeexperimente berücksichtigt. Damit ist ein wiederholter Einsatz der DNA-Elektroden möglich, was einen deutlichen Vorteil im Gegensatz zu bisherigen Systemen bedeutet.

Zur Charakterisierung der Qualität der hergestellten Elektroden wurde die Standardabweichung des Peakstroms von 30 verschiedenen DNA-Sensoren nach der ersten Hybridisierung der Oberfläche mit 10 pM komplementärer, MB-markierter Ziel-DNA bestimmt. Der Pekstrom-Mittelwert konnte mit $330 \pm 80 \mathrm{nA}$ und das dazugehörige Potenzial für MB mit $250 \pm 7 \mathrm{mV}$ berechnet werden (DPV-Messungen). Die geringen Standardabweichungen zeigen die hohe Reproduzierbarkeit des Senorsystems.

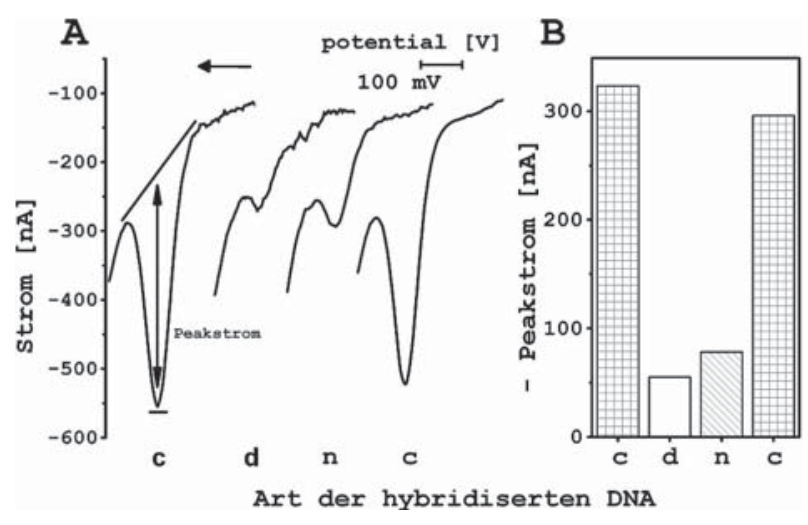

Abb. 2: A) DPV-Messungen eines Sensors mit verschiedenen komplementären (c) und nicht komplementären ( $n$ ) DNA-Sequenzen sowie Messung des Sensors nach der Denaturierung (d) zur Untersuchung der unspezifischen Bindung. B) Darstellung der Peakströme dieser Messungen.

\section{Quantifizierung von Einzelstrang-DNA im direkten Ansatz}

Zur Ermittlung der Sensitivität der Sensoren wurde die Oberfläche der DNA-modifizierten Elektroden verschiedenen Konzentrationen an MB-gelabelter ssDNA ausgesetzt. In Abbildung 3A und 3B sind die Ergebnisse der DPV-Messungen der verschiedenen Experimente dargestellt. Wie erwartet nahm der Peakstrom mit geringeren Konzentrationen an ssDNA ab. Der charakteristische Halbmaximalwert, gerechnet über alle Elektroden, wurde für $170 \pm 25$ nM DNA gefunden. Der lineare Bereich der Konzentrationskurve, welcher zur Quantifizierung von ssDNA benutzt werden kann, liegt zwischen $30 \mathrm{nM}$ und $3 \mu \mathrm{M}$ DNA. Das untere Detektionslimit wurde mit $30 \mathrm{nM}$ DNA bestimmt, was 30 pmol DNA in $1 \mathrm{ml}$ Lösung entspricht. In der Literatur werden zum Teil deutlich geringere Nachweisgrenzen von verschiedenen Autoren beschrieben [26-29]. Der besondere Vorteil der hier beschriebenen Sensoren liegt jedoch in ihrer Wiederverwendbarkeit bzw. Kalibrierbarkeit.

\section{Quantifizierung im kompetitiven Ansatz}

Um auch unbekannte Mengen nicht-markierter ssDNA analysieren zu können, wurde ein kompetitiver Assay entwickelt. Bei einem kompetitiven Ansatz wird die Menge der zu bestimmenden, unmarkierten ssDNA mit Hilfe einer bekannten Menge an MB-markierter ssDNA (Kompetitor) bestimmt. Das Prinzip dieses Ansatzes ist in Abbildung 1B dargestellt. Die DPV-Peakströme verschiedener Gemische von unmarkierter (zu bestimmender) ssDNA und MB-markierter ssDNA (Kompetitor) sind in Abbildung 3C gezeigt. Der größte Peakstrom konnte nach der Inkubation des Sensors mit $1 \mu \mathrm{M}$ 

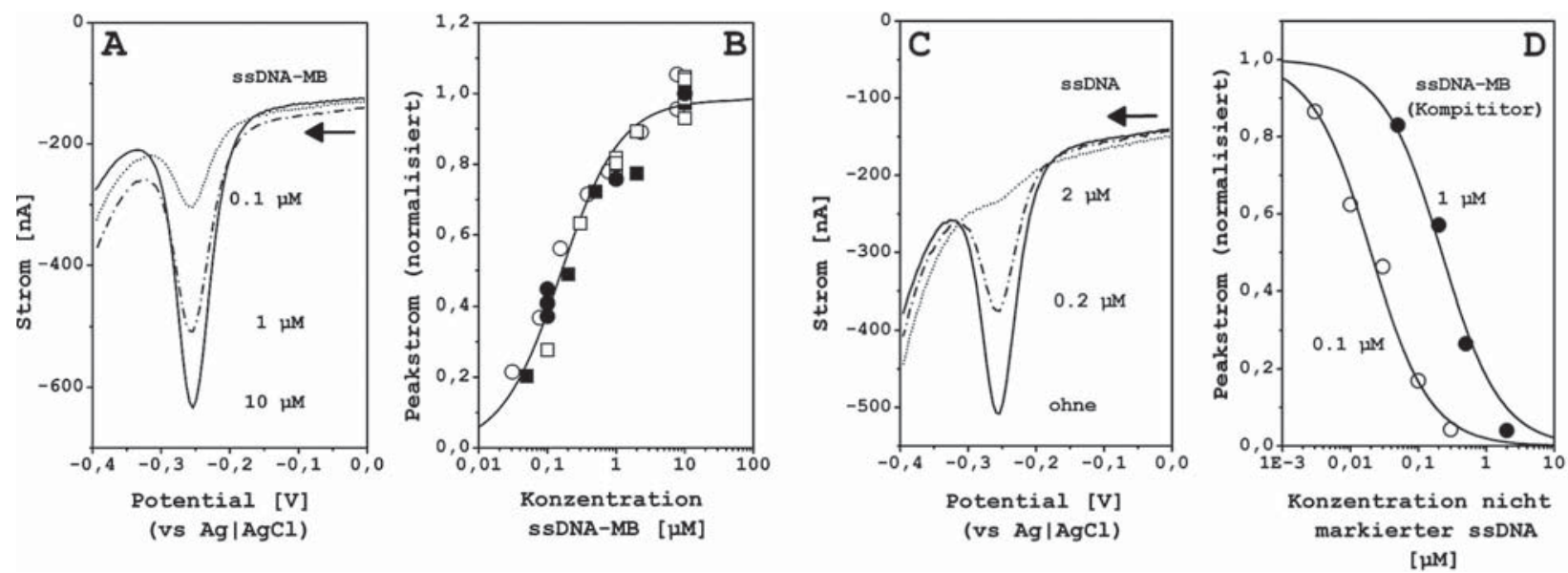

Abb. 3: A) Vergleich von direktem und kompetitivem Quantifizierungsassay. DPV-Signale eines direkten Ansatzes nach Inkubation des Sensors mit verschiedenen Konzentrationen an Ziel-DNA und B) konzentrationsabhängiger Auftrag des resultierenden Peakstroms. Dargestellt in Bild C sind die DPV Signale eines kompetitiven Ansatzes nach Inkubation eines Sensors mit $1 \mu$ M MB-markierter und verschiedenen Konzentrationen unmarkierter Ziel-DNA. Bild D zeigt die Konzentrationsabhängigkeit des gemessenen Peakstroms.

markierter Kompetitor-DNA ohne unmarkierte DNA gemessen werden. Die Zugabe von 0,2 $\mu \mathrm{M}$ unmarkierter DNA führte zu einer Verringerung und eine Zugabe von $2 \mu \mathrm{M}$ zu einer Löschung des Peakstroms. Diese Ergebnisse zeigen, dass die unmarkierte DNA mit dem Kompetitor um die Bindungsplätze der DNA-Fänger konkurriert und deshalb eine eindeutige Konzentrationsbestimmung von unmarkierter DNA möglich ist.

In Abbildung 3D sind die Peakströme zwei verschiedener Versuchsansätze (Zugabe von 0,1 $\mu \mathrm{M}$ oder $1 \mu \mathrm{M}$ Kompetitor-DNA) gezeigt. Wie erwartet steigt der Peakstrom mit sinkender Konzentration an nicht markierter, zu bestimmender ssDNA an. Je geringer die Menge an markierter DNA (Kompetitor) in der Lösung ist, desto weniger unmarkierte DNA-Moleküle werden benötigt, um die Bindung der gelabelten DNA-Moleküle mit dem Fänger auf der Oberfläche zu verhindern. Damit ist es möglich, den Sensitivitätsbereich des Assays mit der Konzentration an MB-markierter Kompetitor-DNA einzustellen. Die Zugabe von 0,1 $\mu \mathrm{M}$ markierter Kompititor-DNA lässt die Detektion von $3 \mathrm{nM}$ nicht markierter, d. h. nachzuweisender ssDNA mit einem Halbmaximalwert bei $20 \pm 2 \mathrm{nM}$ DNA zu.

Der kompetitive Ansatz, bei dem die MB-markierte DNA ausschließlich als Reportermolekül eingesetzt wird, stellt damit nicht nur eine Methode dar, um kleine Mengen DNA nachzuweisen, sondern bietet auch den Vorteil, dass die Proben-DNA vor der Analyse nicht markiert werden muss. Der Nachweis von DNA aus Amplifizierungsprotokollen wie der PCR ist auf diesem Weg möglich.

\section{Detektion von einzelnen Basenfehlpaarungen}

Neben der Quantifizierung von ssDNA ist die Detektion von verschiedenen Basenfehlpaarungen innerhalb der Fänger oder Zielsequenzen ebenfalls möglich. In einem kompetitiven Versuchsansatz wurden verschiedene Fehlpaarungen an verschiedenen Stellen der Sequenzen getestet (s. Tabelle 1 und Abb. 4A). In Abhängigkeit von der Art und Lage der Fehlpaarungen ergaben sich folgende Abhängigkeiten für die mit Hilfe der DPV gemessenen Peakströme: $\mathrm{c}<\mathrm{AC} \leq \mathrm{GG} \approx \mathrm{TT}<$ $\mathrm{GA}<\mathrm{GT}<\mathrm{n}=0$ (s. Abb. 4B). Offensichtlich kommt es in diesem kompetitiven Ansatz auf Grund der einzelnen Mismatches $\mathrm{zu}$ einer verringerten Bindungsaffinität der nicht-markierten Zielsequenzen mit den Fängersequenzen. Je geringer das Bestreben der nichtmarkierten DNA zur Hybridisierung mit der Fänger-DNA ist, desto weniger stark kann diese die Bindung der markierten verhindern. Als Folge dessen erhöhen sich die Peakströme beim Vorhandensein von Basenfehlpaarungen im Vergleich zur Hybridisierung mit komplett komplementärer ssDNA.

Da die Signale der durchgeführten DPV-Experimente eine hohe Reproduzierbarkeit aufwiesen, scheint diese Methode geeignet, um z. B. in der klinischen Diagnostik Basenfehlpaarungen nachzuweisen. Weiterhin ist es auch möglich, eine erste Einschätzung der Art und Lage eines Mismatches zu erhalten. Nochmals sei darauf hingewiesen, dass die Messungen mit unmarkierten DNA-Strängen durchgeführt werden können. 

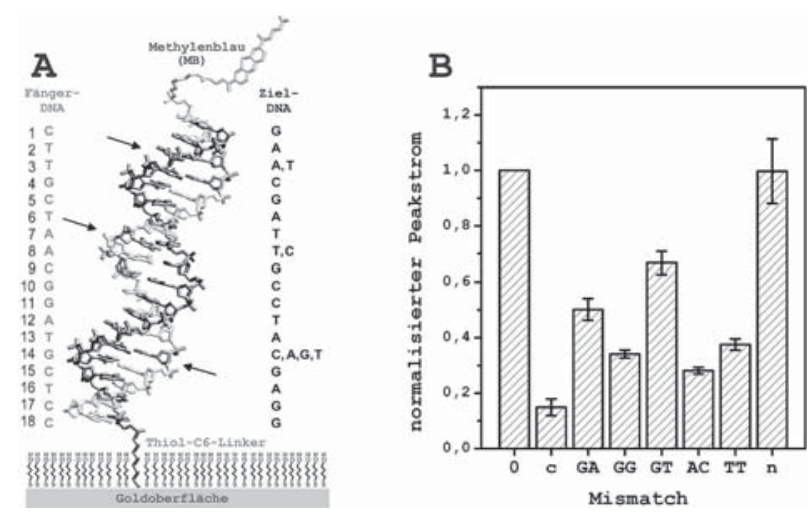

Abb. 4: A) Lage und Art der Fehlpaarungen des 18mer DNA-Fängers. B) Peakströme der voltammetrischen Detektion von verschiedenen, einzeln getesteten Basenfehlpaarungen an unterschiedlichen Stellen der nachzuweisenden DNA-Sequenz in einem kompetitiven Assay.

\subsection{Impedimetrische DNA-Detektion}

Die Sensorpräparation für die impedimetrischen Versuchsreihen erfolgte wie bei den voltammetrischen Experimenten. Zur Charakterisierung der hergestellten Sensoren vor Verwendung in impedimetrischen Messungen wurde zunächst ebenfalls die DNA-Oberflächenbelegung, wie in Abschnitt 3.1 beschrieben, bestimmt. Durch eine Modifizierung des MCB-Passivierungsschrittes konnte die Belegung im Vergleich zu den voltammetrischen Experimenten auf 5-8 pmolcm $^{-2}$ erhöht werden. Nach der Denaturierung der Sensoroberfläche war diese für folgende impedimetrische Experimente bereit.

Beim impedimetrischen DNA-Nachweis wird der Widerstand für die Redoxumwandlung eines Redoxsystems an einer Elektrode bestimmt. Dabei erhöht sich bei der Wahl einer negativ geladenen Redoxspezies (z. B. $\left.\left[\mathrm{Fe}(\mathrm{CN})_{6}\right]^{3-} /\left[\mathrm{Fe}(\mathrm{CN})_{6}\right]^{4-}\right)$ der Widerstand des Sensors nach erfolgter Hybridisierung. Durch die Hybridisierung des negativen DNA-Einzelstrangs mit dem ebenfalls negativ geladenen Zielstrang wird die Ladung auf der Oberfläche des Sensors deutlich erhöht. Negativ geladene Hexacyanoferrat-Ionen werden dadurch an der Abgabe und Aufnahme ihrer Elektronen an der Sensoroberfläche gehindert (s. Abb. 5). Der zu messende Durchtrittswiderstand an der Elektrode erhöht sich deutlich. Dies kann in der sogenannten Nyquist-Darstellung der Impedanz in einfacher Weise an der Zunahme des Durchmessers des Halbkreises erkannt werden (s. Abb. 6A) und wird quantitativ durch eine Anpassung (Fit) der Messdaten anhand eines Ersatzschaltbildes (s. Abb. 6A Inlet) ermittelt. Die Analyse aller Impedanzspektren, die in dieser Versuchsreihe vermessen wurden $(n=35)$ zeigten, dass eine Hybridisierung mit $10 \mu \mathrm{M}$ nicht markierter 18mer ssDNA zu einer Verdreifachung des Durchtrittswiderstandes führt. Als Messgröße für die impedimetrische DNA-Detektion wurde die relative Änderung des Durchtrittswiderstandes gewählt $\left(\mathrm{R}_{\mathrm{CT}}=\right.$ $\mathrm{R}_{\mathrm{CTh}} / \mathrm{R}_{\mathrm{CTd}} ; \mathrm{R}_{\mathrm{CTh}}=$ Durchtrittswiderstand nach der Hybridisierung, $\mathrm{R}_{\mathrm{CTd}}=$ Durchtrittswiderstand nach der Denaturierung).

Die Schlussfolgerung, dass die negative Ladung der immobilisierten DNA die Änderung des Durchtrittwiderstandes beeinflusst, legte nahe, dass auch die $\mathrm{Zu}$ sammensetzung des Messpuffers die Sensitivität der impedimetrischen Messungen beeinflussen könnte. Versuchsreihen mit verschiedenen Konzentrationen an Phosphatpupper ergaben die größten relativen Änderungen bei Verwendung von Pufferkonzentrationen im Bereich 50 - 100 nM.

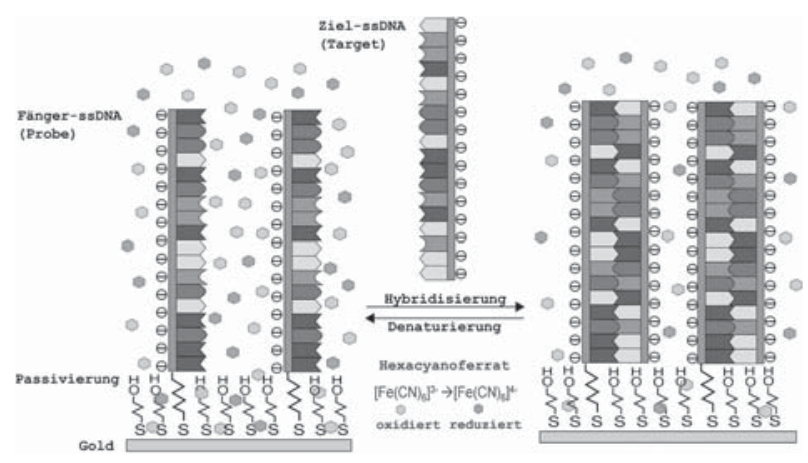

Abb. 5: Darstellung des Messprinzips eines impedimetrischen DNA-Sensors.

\section{Spezifität und Sensitivität der impedimetrischen DNA-Detektion}

Die abwechselnde Hybridisierung des Sensors mit komplementärer und nicht-komplementärer ssDNA zeigte die hohe Spezifität der DNA-Elektrode. Die Inkubation mit komplementärer Ziel-DNA erzeugte einen erhöhten Widerstand, wohingegen die Hybridisierung mit nicht komplementärer ssDNA keinen Effekt aufzeigte (s. Abb. 6B). Dieses bedeutet, dass die MCB-Passivierungsschicht eine unspezifische Bindung von DNA-Targets an die Sensoroberfläche verhindert.

Um die entwickelten Sensoren auch für eine Anwendung (z. B. die Quantifizierung von unbekannten Mengen DNA) zugänglich zu machen, wurden die Detektionsgrenzen des Assays bestimmt. Die Sensoroberfläche wurde dazu verschiedenen Konzentrationen an komplementärer 18mer Ziel-DNA ausgesetzt. Die Ausgefüllten Punkte der Abbildung 7A zeigen die normalisierten Widerstandsänderungen in Abhängigkeit von der ssDNA-Konzentration. Die Bindungskurve zeigte 
einen halbmaximalen Wert bei $350 \pm 40 \mathrm{nM}$ ssDNA, was bedeutet, dass die Sensitivität der impedimetrisch gemessenen DNA-Elektrode im gleichen Bereich liegt wie die des voltammetrisch vermessenen Sensors, der einen Redoxmarker zur Detektion verwendet. Der lineare Bereich der Kurve, der für eine Quantifizierung verwendet werden kann, liegt zwischen $0,1 \mu \mathrm{M}$ und $1 \mu \mathrm{M}$ ssDNA, was für eine Detektion von DNA aus Amplifizierungsprotokollen wie der PCR ausreichend ist.
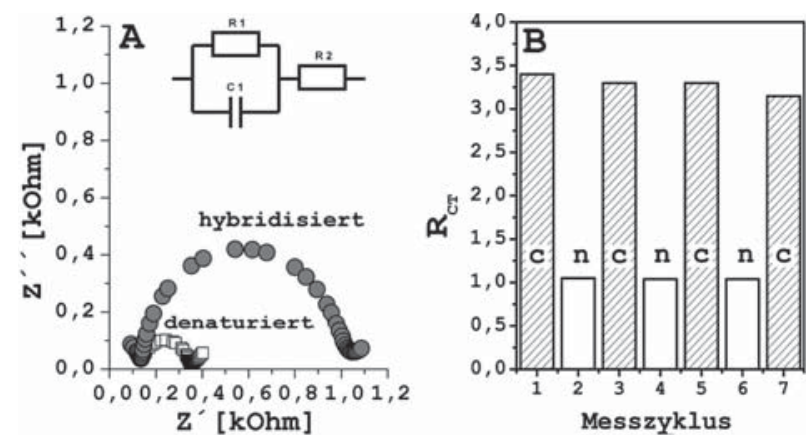

Abb. 6: A) Nyquistdiagramm der Messung des Sensors vor (denaturiert) und nach Hybridisierung mit komplementärer ssDNA. Die Auftragung der durch Analyse mit einem Ersatzschaltbild (Inlet in A) gewonnenen Durchtrittswiderstände nach der Hybridisierung mit komplementärer DNA (c) ist in B sichtbar. Es sind zudem die Widerstände von Messungen nach Hybridisierung mit nicht komplementärer DNA (n) aufgetragen. Es erfolgten sieben Messzyklen mit jeweils einem Denaturierungsschritt dazwischen.

\section{Regeneration von DNA-Sensoren}

Um den Einfluss verschiedener Denaturierungsagenzien auf die Regenerationsfähigkeit des Sensors zu bestimmen wurden folgende Lösungen getestet: Isopropanol, 6 M Guanidinhydrochlorid, 0,1 M Natriumcarbonat und 8M Harnstoff. Die darin enthaltenen Stoffe sind bekannt dafür, die DNA-Doppelhelix aufzulösen, und könnten damit geeignet sein, die Ziel-DNA vom Fänger zu lösen und die Oberfläche für weitere Experimente $\mathrm{zu}$ regenerieren. Die Ergebnisse zeigen, dass weder Isopropanol, noch Guanidinhydrochlorid für diesen Zweck geeignet sind, da beide die Oberfläche derart modifizierten, dass nach vier Detektionszyklen keine Unterschiede in den Durchtrittswiderständen von denaturiertem Sensor zu hybridisiertem Sensor messbar waren. Die Denaturierung mit Natriumcarbonat konnte die Funktionalität des Sensors zwar erhalten, erhöhte jedoch die Widerstände innerhalb von vier Zyklen um das Zehnfache. Verantwortlich dafür sind vermutlich Modifikationen an der Sensoroberfläche. Nur geringe Änderungen des Durchtrittswiderstandes verursachte die Regenerierung der Oberfläche mit Harnstoff. Für die in Abbildung 6B gezeigte Versuchsreihe verdoppelte sich für die denaturierte Oberfläche der Durchtrittswiderstand $\mathrm{R}_{\mathrm{CT}}$ innerhalb von sieben Zyklen von $230 \mathrm{k} \Omega$ auf $500 \mathrm{k} \Omega$. Neben der Signalstabilität verringerte der Einsatz von Harnstoff zudem die benötigte Zeit bei der Messung, da die Denaturierung in diesem Fall nur $30 \mathrm{~s}$ benötigt. Zu der Zeitersparnis bei der Denaturierung konnte zudem in kinetischen Studien nachgewiesen werden, dass die Hybridisierung mit einem 18mer bei Raumtemperatur bereits nach 5 min abgeschlossen ist. Somit summiert sich die Gesamtzeit eines Analysezyklusses auf $15 \mathrm{~min}$.

\section{Nachweis von einzelnen Basenfehlpaarungen mit Hilfe der EIS}

Neben der Quantifizierung von unmarkierter DNA unbekannter Konzentration ist die Verwendung dieser Sensoren für den Nachweis von einzelnen Basenfehlpaarungen ein weiteres Beispiel für deren Nutzten. Dazu wurden die bereits bei der voltammetrischen Mismatchdetektion beschriebenen Fehlpaarungen getestet (s. Tab 1). Die dabei für die Inkubation verwendete Ziel-DNA-Konzentration wurde für diese Experimente von $10 \mu \mathrm{M}$ auf $30 \mu \mathrm{M}$ ssDNA erhöht. Abbildung 7B zeigt die Ergebnisse dieser Versuchsreihe. Alle Hybridisierungen mit Fehlpaarungen enthaltenden ssDNA-Strängen führten zu geringeren Durchtrittswiderständen. Dabei sinkt der Wert im Vergleich zur komplett komplementären Sequenz umso mehr, je geringer der Abstand zwischen Mismatch und der Elektrodenoberfläche ist.

Um auszuschließen, dass die Verringerung der Signale durch eine verringerte Bindungsaffinität der ssDNATargets hervorgerufen wurde, wurde mit der DNA-Sequenz, die einen GT-Mismatch an Position 14 enthielt, eine Bindungskurve aufgenommen (Abb. 7A ungefüllte Messpunkte). Im Vergleich zu der zuvor aufgenommenen Kurve zur Bestimmung der Sensoreigenschaften zeigt der Mismatchstrang eine geringere Affinität. Der Halbmaximale Wert wurde bei $850 \pm 90 \mathrm{nM}$ ssDNA gefunden, was etwa dem doppelten Wert der komplementären DNA entspricht (350 $\pm 40 \mathrm{nM})$. Die für die Mismatch-Experimente gewählte Konzentration von $30 \mu \mathrm{M}$ ssDNA stellt jedoch eine Sättigung der auf Sensoroberfläche befindlichen Fängermoleküle dar, womit sichergestellt ist, dass die gemessenen Effekte nicht auf Grund von geringeren Bindungsaffinitäten verursacht wurden. Die verringerten Werte kommen vielmehr durch strukturelle Änderungen des Doppelstranges zu Stande. 
Bisherige Studien, die sich mit der impedimetrischen Detektion von einzelnen Basenfehlpaarungen beschäftigten, zogen Änderungen in der Bindungsaffinität nicht in Betracht. Sie benutzten komplexer aufgebaute Elektroden und/oder Amplifikationsprotokolle: z. B. die Verwendung eines leitfähigen Polymerfilms für die Immobilisierung der Fänger-DNA und Signalweiterleitung [30] oder nachfolgende Bindungsschritte mit negativ geladene Liposomen für die Signalverstärkung [31]. In der Studie von Long et al. benötigten diese, um Fehlpaarungen zu detektieren, einen Zwischenschritt, in dem sie die B-Typ DNA in M-Typ DNA umwandelten [32]. Mit Hilfe der hier gezeigten Methodik der impedimetrischen Mismatchdetektion ist es möglich Basenfehlpaarungen ohne die oben genannten komplexen Elektroden durchzuführen.
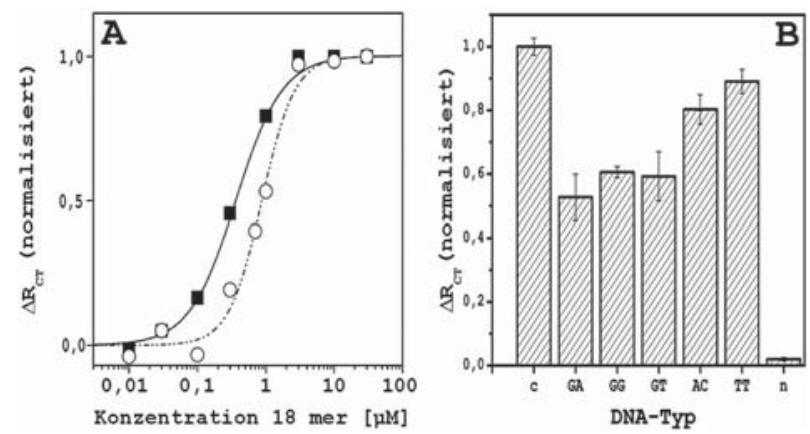

Abb. 7: A) Konzentrationsabhängige Darstellung der gemessenen Durchtrittswiderstände bei verschiedenen Ziel-DNA-Konzentrationen (gefüllte Messpunkte) sowie die Bindungskurve der DNA-Sequenz mit einem GT-Mismatch an Position 14. B) Detektion der bereits mit voltammetrischen Methoden vermessenen Basenfehlpaarungen an unterschiedlichen Stellen der nachzuweisenden DNA-Sequenz in einem direkten Ansatz.

\section{Zusammenfassung}

Die schnelle und spezifische Analyse von Nukleinsäuresequenzen ist in der klinischen Anwendung, in der Landwirtschaft sowie in der Grundlagenforschung unverzichtbar. Dabei kommt es neben dem spezifischen Nachweis von DNA-Sequenzen auch auf eine Quantifizierung und den Nachweis von einzelnen Basenfehlpaarungen an. Die hier vorgestellte Methodik zur Präparation von DNA-modifizierten Elektroden zur Charakterisierung von DNA-Sequenzen bietet in Kombination mit den Methoden der voltammetrischen Detektion oder Impedanzspektroskopie die Möglichkeit, spezifisch, schnell und kostengünstig ssDNA zu quantifizieren und zudem einzelne Basenfehlpaarungen innerhalb der Sequenz zu detektieren. Die Präparation und das Auslesen der Sensoren können ohne großen aparativen Aufwand und ohne zusätzliche Temperierschritte bei Raumtemperatur erfolgen. Die Sensitivität des Nachweises ist ausreichend, um DNA aus Amplifizierungsprotokollen nachzuweisen und kann mit einer Analysezeit von 15 min als zeitsparend beschrieben werden. Mit der Wahl eines kompetitiven Ansatzes bzw. der Detektion mit Hilfe der Impedanzspektroskopie kann der Schritt der Probenmarkierung entfallen. Einen zusätzlichen Vorteil bietet die Wiederverwendbarkeit der Sensoren. In den hier gezeigten Studien war es möglich, die Elektroden mit nur einem geringen Signalverlust bis zu 12-mal zu regenerieren.

Aufbauend auf diesen Ergebnissen sind weitere Experimente möglich. Dabei stehen vor allem die Senkung der unteren Nachweisgrenze, eine Vergrößerung der Arbeitsstabilität und eine Erhöhung der Parallelität der Analyse im Vordergrund.

\section{Literatur}

[1] Peterson, A. W./Wolf, L. K./Georgiadis, R. M. in: Journal of The American Chemical Society (2002), 124(49): p. 14601-14607.

[2] Heller, M. J. in: Annual Review of Biomedical Engineering (2002), 4: p. 129-153.

[3] Reichert, J./Csaki, A./Kohler, J. M./Fritzsche, W. in: Analytical Chemistry (2000), 72(24): p. 6025-6029.

[4] Sauer, S. in: Clinica Chimica Acta (2006), 363(1-2): p. 95-105.

[5] Willner, I./Patolsky, F./Weizmann, Y./Willner, B. in: Talanta (2002), 56(5): p. 847-856.

[6] Wang, R. H./Minunni, M./Tombelli, S./Mascini, M. in: Biosensors \& Bioelectronics (2004), 20(3): p. 598-605.

[7] Diculescu, V. C./Paquim, A. M. C./Brett, A. M. O. in: Sensors (2005), 5(6-10): p. 377-393.

[8] Albers, J./Grunwald, T./Nebling, E./Piechotta, G./Hintsche, R. in: Analytical and Bioanalytical Chemistry (2003), 377(3): p. 521-527.

[9] Gooding, J. J. in: Electroanalysis (2002), 14(17): p. 1149-1156.

[10] Palecek, E./Fojta, M./Jelen, F. in: Bioelectrochemistry (2002), 56(12): p. 85-90.

[11] Lisdat, F./Ge, B./Krause, B./Ehrlich, A./Bienert, H./Scheller, F. W. in: Electroanalysis (2001), 13: p. 1225-1230.

[12] Wang, J. in: Nucleic Acids Research (2000), 28(16): p. 3011-3016.

[13] Steel, A. B./Herne, T. M./Tarlov, M. J. in: Analytical Chemistry (1998), 70(22): p. 4670-4677.

[14] Maruyama, K./Motonaka, J./Mishima, Y./Matsuzaki, Y./Nakabayashi, I./Nakabayashi, J. in: Sensors and Actuators B-Chemical (2001), 76(1-3): p. 215-219.

[15] Wang, J./Cai, X. H./Rivas, G./Shiraishi, H./Farias, P. A. M./ Dontha, N. in: Analytical Chemistry (1996), 68(15): p. 2629-2634.

[16] Ozkan, D./Kara, P./Kerman, K./Meric, B./Erdem, A./Jelen, F./ Nielsen, P. E./Ozsoz, M. in: Bioelectrochemistry (2002), 58(1): p. 119-126.

[17] Kelley, S. O./Barton, J. K./Jackson, N. M./Hill, M. G. in: Bioconjugate Chemistry (1997), 8(1): p. 31-37. 
[18] Hashimoto, K./Ito, K./Ishimori, Y. in: Analytica Chimica Acta (1994), 286(2): p. 219-224.

[19] Thorp, H. H. in: Trends in Biotechnology (1998), 16(3): p. 117-121.

[20] Pan, S. L./Rothberg, L. in: Langmuir (2005), 21(3): p. 1022-1027.

[21] Berggren, C./Stalhandske, P./Brundell, J./Johansson, G. in: Electroanalysis (1999), 11(3): p. 156-160.

[22] Riddles, P. W./Blakeley, R. L./Zerner, B. in: Methods in Enzymology, (1983), 91: p. 49-60.

[23] Boon, E. M./Barton, J. K./Bhagat, V./Nersissian, M./Wang, W./ Hill, M. G. in: Langmuir (2003), 19(22): p. 9255-9259.

[24] Georgiadis, R./Peterlinz, K. P./Peterson, A. W. in: Journal of The American Chemical Society (2000), 122(13): p. 3166-3173.

[25] Herne, T. M./Tarlov, M. J. in: Journal of The American Chemical Society (1997), 119(38): p. 8916-8920.

[26] Carpini, G./Lucarelli, F./Marrazza, G./Mascini, M. in: Biosensors \& Bioelectronics (2004), 20(2): p. 167-175.

[27] Fan, C. H./Plaxco, K. W./Heeger, A. J. in: Proceedings of The National Academy of Sciences of The United States of America (2003), 100(16): p. 9134-9137.

[28] Park, N./Hahn, J. H. in: Analytical Chemistry (2005), 77(21): p 7100-7100.

[29] Wang, J./Kawde, A. N./Musameh, M./Rivas. G. in: Analyst (2002), 127(10): p. 1279-1282

[30] Gu, H. R./di Su, X./Loh, K. P. in: Journal of Physical Chemistry B (2005), 109(28): p. 13611-13618.

[31] Patolsky, F./Lichtenstein, A./Willner, I. in: Journal of The American Chemical Society (2001), 123(22): p. 5194-5205.

[32] Long, Y. T./Li, C. Z./Sutherland, T. C./Kraatz, H. B./Lee, J. S. in: Analytical Chemistry (2004), 76(14): p. 4059-4065.

\section{Autoren}

Dr. rer. medic. Sandra M. Bütow

Technische Fachhochschule Wildau

Fachbereich Ingenieurwesen/Wirtschaftsingenieurwesen

Biosystemtechnik

Tel. +493375 508-137

sandra.buetow@tfh-wildau.de

Dr. rer. nat. Oliver Pänke

oliver.paenke@web.de

Jan Kafka, M. Sc.

Danmarks Tekniske Universitet, Lyngby

Department of Micro- and Nanotechnology

jan.kafka@nanotech.dtu.dk

Prof. Dr. rer. nat. habil. Fred Lisdat

Technische Fachhochschule Wildau

Fachbereich Ingenieurwesen/Wirtschaftsingenieurwsen

Biosystemtechnik

fred.lisdat@tfh-wildau.de 